Pesq. Vet. Bras. 30(5):389-397, maio 2010

\title{
Aspectos epidemiológicos e padrões de lesões hepáticas em 35 surtos de intoxicação por Senecio spp. em bovinos no sul do Rio Grande do Sul ${ }^{1}$
}

\author{
Fabiane B. Grecco ${ }^{2}$, Ana L. Schild ${ }^{3 *}$, Mauro P. Soares ${ }^{3}$, Clairton Marcolongo- \\ Pereira $^{4}$, Pablo Estima-Silva ${ }^{5}$ e Eliza S.V. Sallis ${ }^{2}$
}

\begin{abstract}
Grecco F.B., Schild A.L., Soares M.P., Marcolongo-Pereira C., Estima-Silva P. \& Sallis E.S.V. 2010. [Epidemiological aspects and hepatic lesions pattern in 35 outbreaks of Senecio spp. poisoning in cattle in southern Brazil.] Aspectos epidemiológicos e padrões de lesões hepáticas em 35 surtos de intoxicação por Senecio spp. em bovinos no sul do Rio Grande do Sul. Pesquisa Veterinária Brasileira 30(5):389-397. Laboratório Regional de Diagnóstico, Faculdade de Veterinária, Universidade Federal de Pelotas, Campus Universitário, Pelotas, RS 96010-900, Brazil. E-mail: alschild@terra.com.br

The study aimed to characterize morphological patterns of 59 liver samples of Senecio spp. poisoned cattle from 35 outbreaks, observed in southern Rio Grande do Sul, Brazil, from 2000 to 2009. The lesions were associated with epidemiological changes during these years. The climate changes concerning accumulated rain and mean temperature during the different seasons were analyzed. The macroscopic and histological lesions were classified into 6 different patterns. The macroscopic classification was made according to capsular pattern, hepatic cut surface discoloration, and the presence of nodules. The histological classification was based on the distribution of fibrosis, the amount of megalocytes in 10 high magnification fields, and on bile duct proliferation. Pattern 1 was characterized by a whitish liver, diffuse fibrosis, severe bile duct proliferation, and discrete megalocytosis; pattern 2 was characterized by nodules consisting of groups of hepatocytes surrounded by fibrosis, severe bile duct proliferation, and discrete to mild megalocytosis; pattern 3 was characterized by a macro-nodular aspect to the cut surface with hepatic lobules surrounded by a thin septa of fibrous tissue, severe bile duct proliferation, and mild megalocytosis; pattern 4 was characterized by a non-nodular surface with marble aspect, mild to severe bile duct proliferation, and megalocytosis; pattern 5 was characterized by a nonnodular surface and bridging or diffuse fibrosis, mild megalocytosis, and severe bile duct proliferation; and pattern 6 was characterized by a non-nodular surface, severe megalocytosis, discrete bile duct proliferation, and incipient fibrosis of the portal system, central vein or among hepatocyte cords. The results of macroscopic and histological liver analysis showed that patterns 1, 2 and 4 were the most frequently observed. The results of this study demonstrated that the macroscopic lesion observed in Senecio poisoned cattle is variable. Histologically this variation is related to the amount and distribution of fibrosis, megalocytosis and bile duct proliferation observed in each liver. Age of the cattle, evolution period of poisoning and clinical signs did not interfere on the pattern of lesions observed. On the other hand, climatic conditions probably had influence on increased disease prevalence due to major availability of Senecio spp. plants.
\end{abstract}

INDEX TERMS: Senecio spp., hepatotoxicosis, cattle.

${ }^{1}$ Recebido em 6 de novembro de 2009.

Aceito para publicação em 13 de dezembro de 2009.

Parte da Tese de Doutorado do primeiro autor, Programa de PósGraduação em Veterinária, Faculdade de Veterinária, Universidade Federal de Pelotas (UFPel), Campus Universitário s/n, Pelotas, RS 96010900, Brasil.

2Departamento de Patologia Animal, Faculdade de Veterinária, UFPel.

\footnotetext{
${ }^{3}$ Laboratório Regional de Diagnóstico, Faculdade de Veterinária, UFPel. *Autor para correspondência: alschild@terra.com.br

${ }^{4}$ Mestrando do Curso de Pós-Graduação em Veterinária, Faculdade de Veterinária, UFPel, Campus Universitário s/n, Pelotas, RS,

${ }^{5}$ Graduando em Medicina Veterinária, Faculdade de Veterinária, UFPel, Campus Universitário s/n, Pelotas, RS. Bolsista de Iniciação Científica, CNPq.
} 
RESUMO.- O presente estudo teve como objetivo caracterizar os diferentes padrões morfológicos hepáticos em 59 fígados de bovinos intoxicados por Senecio spp. provenientes de 35 surtos observados na área de influência do Laboratório Regional de Diagnóstico da Faculdade de Veterinária da Universidade Federal de Pelotas (LRD) de 2000-2009, dos quais havia registro fotográfico das lesões macroscópicas, fazendo uma relação com as variações epidemiológicas observadas no período. Foram analisadas as variações climáticas referentes à precipitação pluviométrica e temperatura média nas diferentes estações do ano ocorridas neste intervalo de tempo. As alterações hepáticas macro e microscópicas foram agrupadas em padrões morfológicos semelhantes. Foi considerada como critérios de classificação macroscópica a coloração das superfícies capsular e de corte e a presença ou não de nódulos; e como critérios para a classificação histológica a quantidade e distribuição da fibrose, o número de megalócitos por campo de maior aumento, o grau estimado de proliferação de ductos biliares e a presença de hepatócitos vacuolizados. O Padrão 1 caracterizou-se por fígado esbranquiçado, fibrose difusa, acentuada proliferação de células de ductos biliares e megalocitose discreta; o Padrão 2 por presença de nódulos correspondentes a grupos de hepatócitos ou lóbulos hepáticos circundados por tecido conjuntivo fibroso, acentuada proliferação de células de ductos biliares e megalocitose de discreta a moderada; o Padrão 3 por superfície de corte com aspecto macronodular correspondente a lóbulos hepáticos circundados por delgado cordão de tecido conjuntivo, acentuada proliferação de ductos biliares e megalocitose moderada; o Padrão 4 por superfície sem nodulações e com aspecto marmorizado e histologicamente por fibrose em ponte, megalocitose e proliferação de células de ductos de moderadas a acentuadas; o Padrão 5 por superfície sem nodulações e microscopicamente por fibrose em ponte a difusa, megalocitose moderada e acentuada proliferação de células de ductos; e, o Padrão 6 por superfície sem nodulações e microscopicamente por megalocitose acentuada, proliferação de ductos discreta e fibrose em estágio inicial localizada nos espaços porta e veia centrolobular ou como colágeno imaturo entre os cordões de hepatócitos. Os resultados da análise macroscópica e histológica dos fígados dos bovinos demonstraram que os Padrões 1, 2e 4 foram os mais frequentemente encontrados. Os resultados deste trabalho demonstram que a lesão hepática macroscópica que ocorre em bovinos intoxicados por Senecio spp. é variável e que histologicamente esta variação está relacionada à distribuição e a quantidade da fibrose, à quantidade de megalócitos e à proliferação biliar observadas em cada fígado. A idade dos animais, o tempo de evolução da intoxicação e os sinais clínicos não interferem nos padrões de lesões hepáticas encontradas. Por outro lado, as condições climáticas provavelmente tiveram influência no aumento da freqüência da doença devido ao aumento da disponibilidade da planta.

TERMOS DE INDEXAÇÃO: Senecio spp., hepatotoxicose, bovinos.

\section{INTRODUÇÃO}

No Rio Grande do Sul a intoxicação por diversas espécies de Senecio em bovinos tem sido bem documentada (Barros et al.1987, Méndez et al. 1987, 1990, Driemeier et al. 1991, Barros et al. 1992, Méndez \& Riet-Correa 1993, Pedroso et al. 2005). Nesses trabalhos, as lesões hepáticas macroscópicas referem-se a fígados esbranquiçados e firmes cujos aspectos histológicos predominantes incluem megalocitose, proliferação de ductos biliares e fibrose difusa. No entanto, dados sobre os aspectos macroscópicos hepáticos e graduação e distribuição das lesões hepáticas histológicas são escassos (Torres \& Coelho 2008).

Os alcaloides pirrolizidínicos (APs) presentes em plantas do gênero Senecio produzem lesões progressivas e irreversíveis ao fígado, que é o órgão responsável por processos de síntese, excreção e catabolismo. Os sistemas enzimáticos hepáticos de destoxificação, como a citocromo $\mathrm{p}-450$, atuam de forma rápida e têm ampla especificidade, dando ao animal a capacidade de suportar uma grande variedade de insultos causados por toxinas naturais ou sintéticas (Lindamood 1991, Cheeke 2009).

Os danos hepáticos produzidos pelos APs são caracterizados por megalocitose das células parenquimatosas, proliferação de células de ductos biliares e fibrose em grau e distribuição variáveis. Podem ser observados, também, obliteração dos vasos hepáticos venosos de médio e pequeno calibre, e edema subendotelial das veias centrolobulares com pronunciada congestão sinusoidal desta área e necrose de hepatócitos (Berry \& Bras 1957). A morte dos animais ocorre por insuficiência hepática (Jago 1969, Kellerman et al. 2005).

A megalocitose é caracterizada por aumento no tamanho e na proporção núcleo/citoplasma dos hepatócitos, podendo observar-se células com várias vezes o tamanho normal esperado (Jago 1969, Lindamood 1991). Estes megalócitos são originados pelo efeito antimitótico induzido pelos APs e são as primeiras lesões observadas no fígado de animais intoxicados (Torres \& Coelho 2008). Os hepatócitos em megalocitose, apesar de seu tamanho, não conseguem desempenhar as funções normais, tendo, portanto, implicação no desenvolvimento da insuficiência hepática (Jago 1969, Lindamood 1991, Kelly et al. 1993, RietCorrea \& Méndez 2007).

Fígados com morfologia de estágio terminal podem ser observados nos casos de seneciose crônica em bovinos e são caracterizados por fibrose difusa e/ou nódulos hiperplásicos parenquimatosos que podem ser poucos ou numerosos, claros ou escuros, de tamanhos variados e que provocam distorção da arquitetura hepática normal (Karam et al. 2004, Cullen 2007).

Na área de influência do Laboratório Regional de Diagnóstico (LRD), da Faculdade de Veterinária da Universidade Federal de Pelotas (UFPel), surtos da intoxicação por Senecio spp. em bovinos são diagnosticados todos os anos, sendo a segunda causa mais importante de morte de bovinos na região sul do Rio Grande do Sul (Schild et al. 2008) e a planta tóxica mais importante no estado (Rissi et al. 2007).

A grande maioria dos casos diagnosticados na área de influência do LRD/UFPel é caracterizada por lesões macroscópicas e histológicas hepáticas consideradas clássicas, porém com distribuição e severidade variáveis. $\mathrm{O}$

Pesq. Vet. Bras. 30(5):389-397, maio 2010 
objetivo deste trabalho foi descrever os padrões morfológicos hepáticos observados em 35 surtos de intoxicação por Senecio spp. ocorridos na região de abrangência do LRD no período de 2000 a 2009 e discutir a possível relação destes padrões com os aspectos epidemiológicos observados.

\section{MATERIAL E MÉTODOS}

Foi realizado o estudo epidemiológico dos surtos de intoxicação por Senecio spp. em bovinos, ocorridos na área de influência do Laboratório Regional de Diagnóstico (LRD), Faculdade de Veterinária, UFPel, Pelotas, RS, no período de 2000-2009. Dados referentes à precipitação pluviométrica foram obtidos nos boletins agroclimatológicos da Estação Agroclimatológica de Pelotas, Convênio Embrapa/UFPEL/INMET.

A avaliação macroscópica dos fígados foi realizada utilizando-se as descrições constantes nos protocolos de necropsia e por meio de fotografias. Para a avaliação histológica fragmentos do órgão foram fixados em formol a $10 \%$, processados rotineiramente e corados pelas técnicas de hematoxilina e eosina (HE) e tricrômico de Masson (TM). As lesões macroscópicas observados nas fotografias de cada fígado eram descritas e os cortes para estudo histológico eram feitos em áreas representativas das mesmas.

Para a classificação dos diferentes padrões foram adotados critérios levando-se em consideração macroscopicamente: a cor e o aspecto das superfícies capsular e de corte, observandose a presença ou não de nodulações (cor, quantidade, tamanho e distribuição); e histologicamente: a distribuição da fibrose; a quantidade de megalócitos por campo de maior aumento (10 campos em cada lâmina), sendo considerada megalocitose discreta a presença de 1-7 megalócitos/campo (+), megalocitose moderada de 7-15/campo (++) e megalocitose acentuada acima de 15/campo (+++); o grau estimado de proliferação de células de ductos biliares, avaliado em discreto (+), moderado (++) e acentuado $(+++)$; a presença ou não de células hepáticas organizadas em nódulos; a presença ou não de vacúolos nos hepatócitos; e grau estimado de comprometimento vascular (doença veno-oclusiva). As alterações macroscópicas e microscópicas encontradas em cada fígado foram agrupadas em padrões morfológicos semelhantes, sendo que a classificação final em um determinado padrão, quando o aspecto macroscópico não permitia uma classificação única, era definida pela lesão histológica.

\section{RESULTADOS}

A precipitação pluviométrica média observada na região nas diferentes estações do ano no período estudado é apresentada no Quadro 1. Durante o período estudado (2000-2009) foram diagnosticados 93 surtos da intoxicação por Senecio spp. em bovinos na área de influência do LRD/UFPel. Dentre esses, foram selecionados para este estudo 59 fígados dos quais havia registro fotográfico. Esses 59 fígados eram provenientes de bovinos envolvidos em 35 dos 93 surtos diagnosticados. A distribuição desses 35 surtos por ano foi a seguinte: um surto ocorreu em 2001, um em 2004, três em 2006, 14 em 2007, 11 em 2008 e cinco em 2009. A distribuição dos surtos durante os diferentes meses do ano no período estudado encontra-se no Quadro 2.
Quadro 1. Precipitação pluviométrica $(\mathrm{mm})$ nas diferentes estações do ano, entre 2000 e julho de 2009

\begin{tabular}{ccccc}
\hline Ano & $\begin{array}{c}\text { Precipitação } \\
\text { média na } \\
\text { primavera }^{a}\end{array}$ & $\begin{array}{c}\text { Precipitação } \\
\text { média no } \\
\text { verão }^{\text {a }}\end{array}$ & $\begin{array}{c}\text { Precipitação } \\
\text { média no } \\
\text { outono }^{\text {a }}\end{array}$ & $\begin{array}{c}\text { Precipitação } \\
\text { média no } \\
\text { inverno }^{\text {a }}\end{array}$ \\
\hline 2000 & 142,13 & 54,1 & 85,3 & 195,06 \\
2001 & 166,3 & 162,1 & 175,66 & 135,36 \\
2002 & 163,33 & 173,1 & 241,13 & 84,6 \\
2003 & 89,16 & 156,13 & 118,26 & 145,6 \\
2004 & 97,93 & 61,8 & 210,10 & 82,5 \\
2005 & 119,53 & 81,26 & 111,3 & 57,3 \\
2006 & 90,93 & 112,5 & 74,73 & 83,1 \\
2007 & 98,76 & 102,4 & 149,5 & 167,5 \\
2008 & 78,03 & 107,8 & 115,5 & 109,8 \\
2009 & - & 196,43 & 57,36 & - \\
\hline
\end{tabular}

a Média normal para a região em um período de 30 anos: primavera $=$ 111,$3 ;$ verão $=118,7 ;$ outono $=90,5 ;$ inverno $=116,5$.

Em relação à idade dos animais afetados 15 surtos $(42,8 \%)$ ocorreram em animais até três anos de idade sendo um em 2001, um em 2006, 5 em 2007, seis em 2008 e dois em 2009. Dezoito $(51,4 \%)$ ocorreram em animais maiores de três anos de idade sendo um em 2001, um em 2004, dois em 2006, sete em 2007, cinco em 2008 e três em 2009. Em dois surtos observados no ano 2007 foram afetados animais de várias idades.

A evolução dos sinais clínicos foi inferior a sete dias em oito surtos, 7-14 dias em quatro surtos, 15-30 dias em sete surtos, 2-4 meses em quatro surtos, superior a quatro meses em um surto, e em 4 surtos a evolução variou entre 1-20 dias em dois surtos e entre 15-60 dias em outros dois. Em sete surtos não havia dados sobre a evolução da intoxicação nos protocolos de encaminhamento de materiais ao LRD. As taxas médias de morbidade e letalidade foram de $6,9 \%$ e $100 \%$, respectivamente. A partir das lesões macroscópicas e histológicas observadas nos 59 fígados avaliados foram definidos 6 padrões de lesões causadas pela intoxicação por Senecio spp.

Padrão 1. Caracterizado macroscopicamente por fígado esbranquiçado com superfície capsular e de corte sem nodulações (Fig.1A). Histologicamente havia fibrose imatura ou madura, difusa, com hepatócitos remanescentes distribuídos em pequenos grupos ou cordões isolados pelo tecido conjuntivo fibroso (Fig.1B). A megalocitose era discreta, variando de 1-7 por campo e a proliferação de ductos podia variar entre discreta (+), moderada (++) e acentuada $(+++)$. Havia ainda oclusão parcial ou total da luz das veias centrolobulares, necrose individual de hepatócitos e discreto infiltrado inflamatório misto aleatório.

Padrão 2. Caracterizado macroscopicamente por nodulações múltiplas coalescentes (Fig.1C) ou esparsas, de diferentes tamanhos e que variavam de amareladas a castanhas, distribuídas na superfície capsular e de corte. Microscopicamente as nodulações amareladas correspondiam a grupos de hepatócitos tumefeitos com citoplasma vacuolizado circundados por tecido conjuntivo fibroso e os nódulos castanhos correspondiam a lóbulos hepáticos ou grupos de hepatócitos encarcerados por tecido conjuntivo (Fig.1D), que for- 
Quadro 2. Idade, época de ocorrência, evolução dos sinais clínicos e padrão de lesão hepática de 59 fígados provenientes de 35 surtos de intoxicação por Senecio spp. em bovinos diagnosticados no LRD entre 2001 e julho de 2009

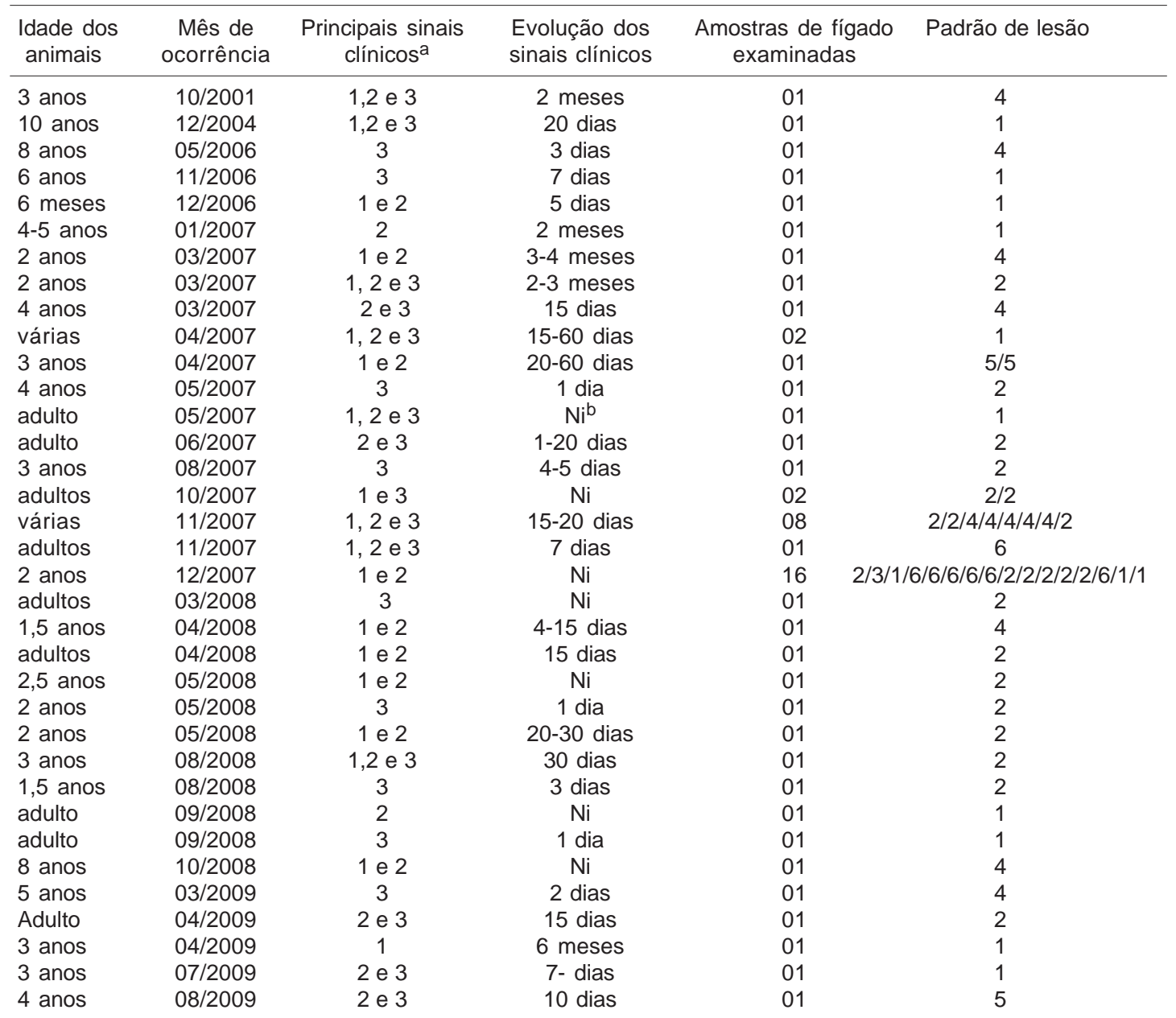

a Sinais clínicos: emagrecimento $=1$, diarréia $=2$, sinais neurológicos $=3$. b $\mathrm{Ni}=$ não informado.

mavam septos delgados ou espessos. Havia, também, fibrose difusa entre os nódulos e acentuada proliferação de células de ductos biliares. A megalocitose variava de discreta $(+)$ a moderada (++). Havia moderado comprometimento por doença veno-oclusiva de vasos intranodulares e internodulares, necrose individual de hepatócitos dos nódulos e infiltrado inflamatório nos septos de tecido conjuntivo.

Padrão 3. Caracterizado macroscopicamente por superfície de corte com aspecto macronodular e de coloração alaranjada (Fig.1E). Microscopicamente havia um ou vários lóbulos hepáticos circundados por delgado cordão de tecido conjuntivo que era mais espesso nos espaçosporta (Fig.1F). No tecido conjuntivo visualizava-se acentuada proliferação de ductos biliares (+++). Os hepatócitos por vezes eram vacuolizados e a megalocitose era moderada (++). Havia moderado comprometimento por doença veno-oclusiva de vasos intranodulares e internodulares, necrose individual de hepatócitos dos nódulos e infiltrado inflamatório nos septos de tecido conjuntivo.
Padrão 4. Caracterizado macroscopicamente por superfície capsular e de corte sem nodulações e com aspecto marmorizado (estriações ou cordões claros intercalados com áreas escuras) (Fig.2A). Microscopicamente havia fibrose em ponte, ou fibrose periportal com áreas em ponte (Fig.3B). A megalocitose e a proliferação de células de ductos variavam de moderadas (++) a acentuadas (+++). Havia necrose hepática focal a coalescente discreta e poucas veias centrolobulares com redução da luz e rodeadas por fibrose (doença veno-oclusiva), e infiltrado inflamatório misto de distribuição aleatória a periportal.

Padrão 5. Caracterizado macroscopicamente por superfície capsular e de corte sem nodulações com áreas avermelhadas intercaladas com áreas amareladas (Fig.2C). Microscopicamente havia fibrose em ponte a difusa, hepatócitos tumefeitos com vacuolização fina do citoplasma, megalocitose moderada $(++)$, acentuada proliferação de células de ductos (+++) (Fig.2D) e áreas de hemorragia. Havia necrose individual de hepatócitos e discreto infiltrado inflamatório misto periportal. 
Padrão 6. Caracterizado macroscopicamente por fígado com superfície capsular e de corte sem nodulações e de coloração levemente avermelhada (Fig.2E). Microscopicamente havia megalocitose acentuada $(+++)$, proliferação de ductos discreta (+) e fibrose em estágio inicial localizada nos espaços porta e veia centrolobular ou como colágeno imaturo entre os cordões de hepatócitos (Fig.2F).
Havia também infiltrado inflamatório multifocal aleatório discreto a moderado e necrose individual de hepatócitos.

Pela coloração de TM observou-se que a fibrose estava distribuída de forma difusa no Padrão 1 (Fig.3A), em septos espessos no Padrão 2 (Fig.3B), em septos delgados no Padrão 3 (Fig.3C), em ponte no Padrões 4 e 5 (Fig.3D-E) e era discreta nos espaços porta e ao redor das
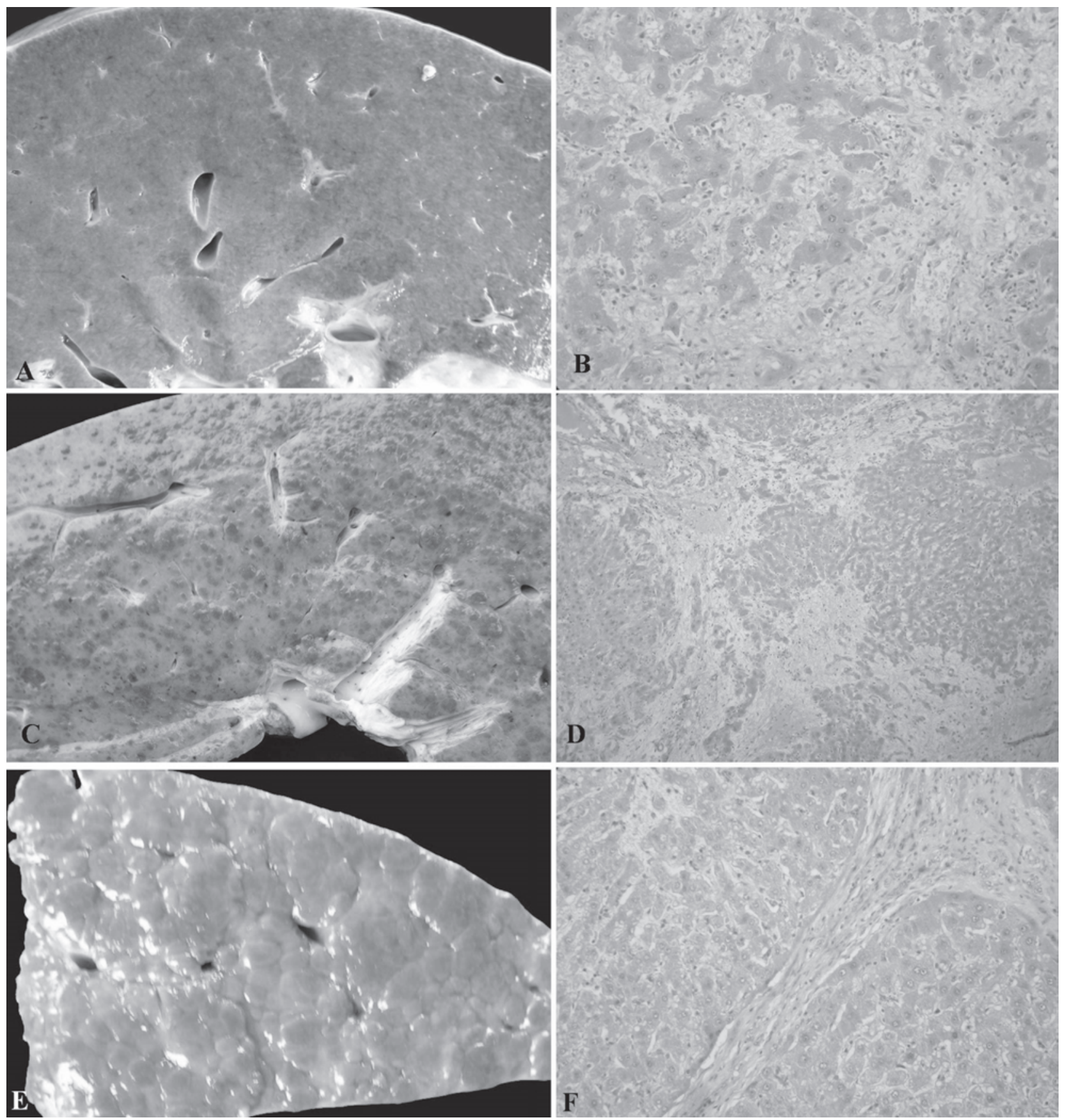

Fig.1. Fígados de bovinos intoxicados por Senecio spp. Padrão 1. (A) Superfície de corte esbranquiçada e sem nodulações. (B) Histologicamente há fibrose difusa com hepatócitos remanescentes distribuídos em grupos ou cordões. HE, obj.20x. Padrão 2. (C) Superfície de corte com múltiplas nodulações de tamanhos variados e coloração castanha. (D) Histologicamente há nódulos de hepatócitos circundados por espessos septos de tecido fibroso. HE, obj.10x. Padrão 3. (E) Superfície de corte alaranjada e com aspecto macronodular. (F) Histologicamente há lóbulos hepáticos ou grandes nódulos circundados por delgado septo de tecido conjuntivo. HE, obj.20x. 
veias centrolobulares no Padrão 6 (Fig.3F). Dos 59 fígados analisados 13 foram classificados no Padrão 1, 23 no Padrão 2, um no Padrão 3, 12 no Padrão 4, três no Padrão 5 e sete no Padrão 6. No Quadro 2 são apresentados os dados relativos à idade dos animais, evolução dos sinais clínicos e classificação do padrão de lesão observado em cada fígado.
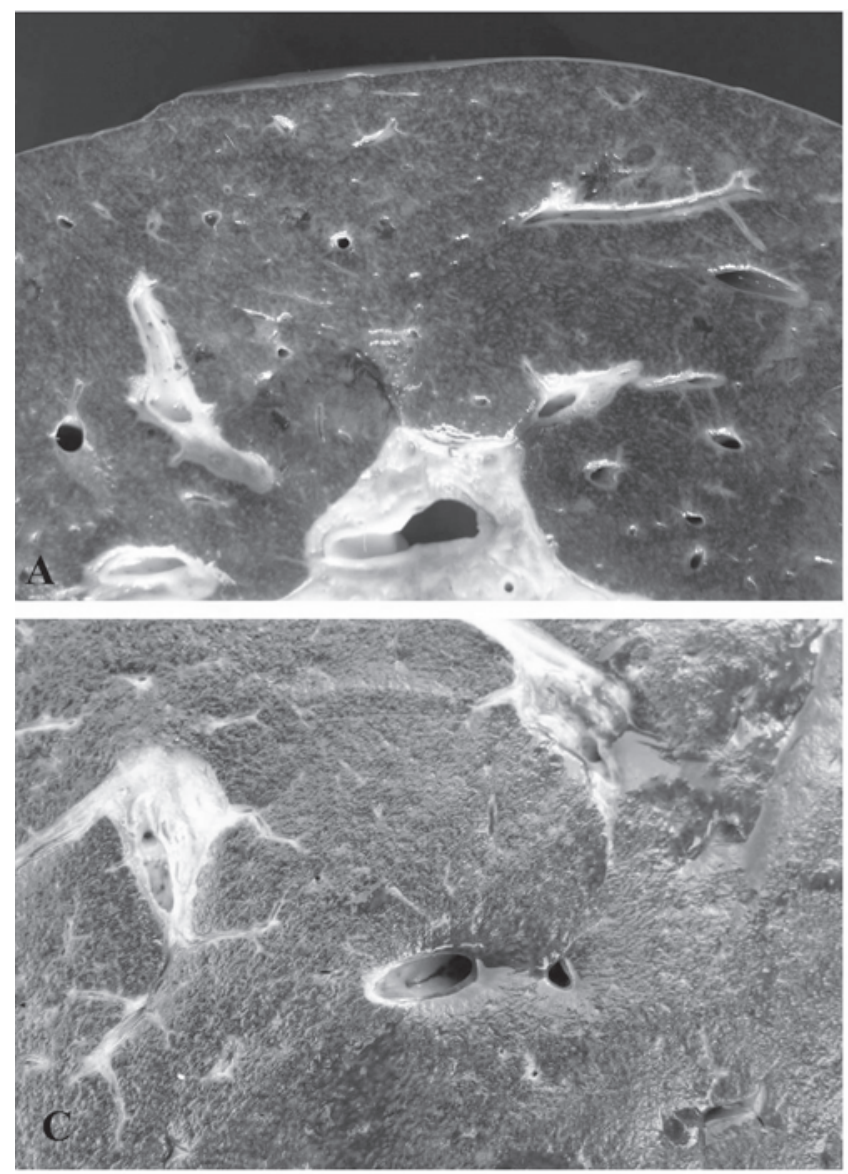

B
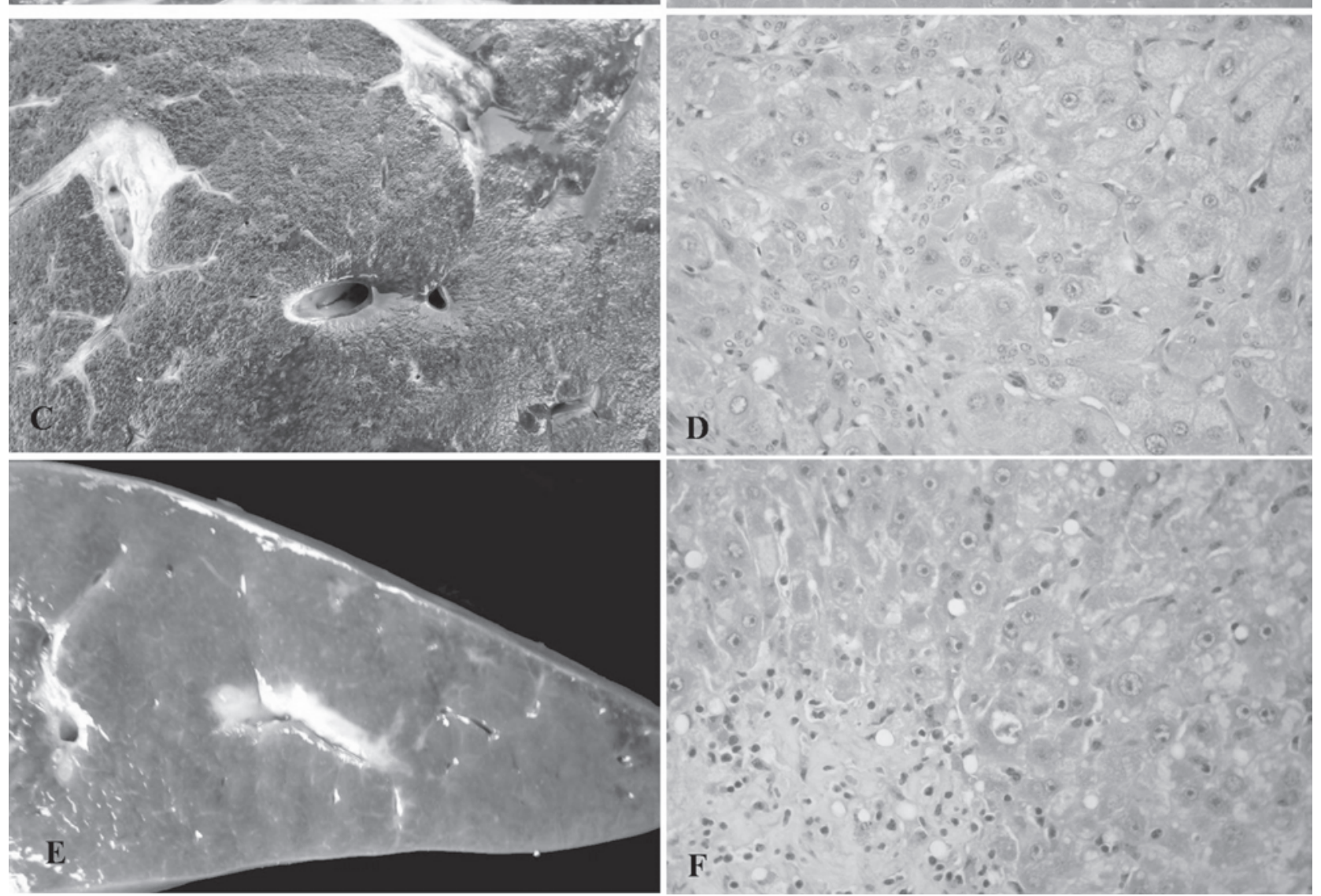

Fig.2. Fígados de bovinos intoxicados por Senecio spp. Padrão 4. (A) Superfície de corte com aspecto marmorizado e sem nodulações. (B) Histologicamente há fibrose em ponte com hiperplasia moderada de células de ductos biliares e discreto infiltrado inflamatório. HE, obj.20x. Padrão 5. (C) Superfície de corte escura com áreas amareladas e sem nodulações. (D) Histologicamente há tumefação de hepatócitos que apresentam vacuolização fina e proliferação acentuada de ductos biliares. HE, obj.40x. Padrão 6. (E) Superfície de corte levemente avermelhada sem nodulações. (F) Histologicamente há megalocitose, retenção biliar e presença de tecido fibroso imaturo. HE, obj.40x. 
As condições climáticas provavelmente influíram no aumento do número de surtos da intoxicação observados principalmente nos anos 2007-2008, porém não puderam ser totalmente relacionadas aos diferentes padrões morfo- lógicos observados nos fígados estudados já que, de modo geral, não houve tendência de ocorrer determinado padrão em um período específico do estudo. Por outro lado, o Padrão 3 foi observado apenas em um fígado no ano 2007 ,
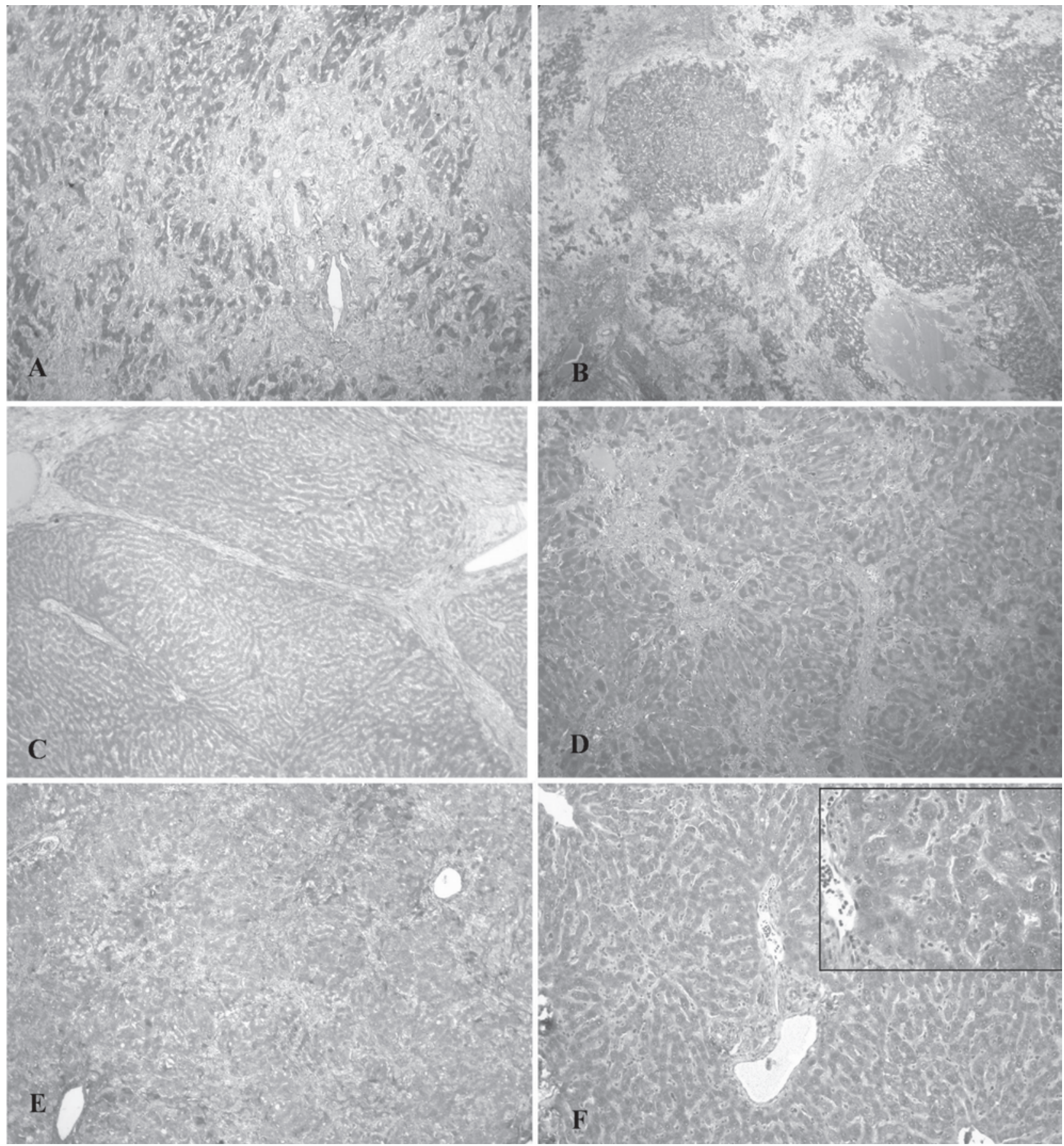

Fig.3. Cortes histológicos de fígados de bovinos intoxicados por Senecio spp. Padrão 1. (A) Fibrose difusa; observam-se grupos ou cordões de hepatócitos separados por tecido conjuntivo fibroso. Tricrômico de Masson, obj.4x. Padrão 2. (B) Há encarceramento de lóbulos por septos de tecido conjuntivo fibroso. Tricrômico de Masson, obj.4x. Padrão 3. (C) Delgados septos de tecido conjuntivo fibroso separando um ou mais lóbulos hepáticos; a fibrose é mais acentuada nos espaços porta. Tricrômico de Masson, obj.4x. Padrão 4. (D) Observam-se septos de tecido conjuntivo fibroso unindo espaços porta e/ou veias centrolobulares. Tricrômico de Masson, obj.4x. Padrão 5. (E) A fibrose apresenta-se de forma similar ao Padrão 4, porém é mais discreta. Tricrômico de Masson, obj.4x. Padrão 6. (F) A fibrose é discreta nos espaços porta; no detalhe há colágeno jovem entre os cordões de hepatócitos. Tricrômico de Masson, obj.10x. 
tendo características únicas que não se enquadraram nos demais padrões em função da quantidade e distribuição da fibrose. O Padrão 6 foi observado, também, somente no ano 2007, no fígado de um bovino morto espontaneamente com sinais clínicos da doença e em seis fígados coletados durante o abate de animais afetados. As lesões neste padrão eram caracterizadas por megalocitose acentuada e fibrose inicial. A apresentação desses padrões de lesão pode estar relacionada ao aumento da toxicidade da planta e a maior quantidade da mesma nas pastagens já que a brotação de Senecio spp. foi permanente durante esse período. Em um trabalho de graduação da fibrose em bovinos intoxicados experimentalmente por Senecio brasiliensis foi demonstrado que a megalocitose e a proliferação de ductos são as primeiras lesões que ocorrem e que a fibrose é diretamente proporcional ao tempo de ingestão da planta (Torres \& Coelho 2008). Dessa forma, aqueles bovinos que apresentaram lesão hepática com megalocitose acentuada provavelmente desenvolveram insuficiência hepática e morreram em conseqüência da intoxicação por Senecio spp. antes que houvesse tempo para o desenvolvimento da fibrose. De acordo com os dados dos últimos 30 anos observou-se que a precipitação pluviométrica acumulada diminuiu a partir de 2004, principalmente nos meses de inverno e de verão. No verão, mesmo quando há chuvas regulares, a evaporação é maior em função das altas temperaturas e maior incidência solar. No inverno, ao contrário, a evaporação é menor (Marques 2009). A partir de 2004 a estiagem foi mais acentuada e pode ter influenciado no aumento da concentração de alcaloides pirrolizidínicos nas plantas do gênero Senecio. Driemeier et al. (1991) observaram, também, aumento no número de surtos em anos posteriores à severa estiagem. Tem sido mencionado que as condições ambientais, como seca e alta temperatura, aumentam o teor de alcalóides pirrolizidínicos nas plantas e, portanto, determinadas espécies de Senecio podem ser mais tóxicas dependendo do ambiente e de suas variáveis (Tokarnia et al. 2000, Karam et al. 2004). Além disso, a escassez de forragem observada em período de estiagem prolongada nas condições de criação de bovinos na região sul do RS pode afetar o processo de destoxificação dos alcaloides pirrolizidínicos. Tem sido demonstrado em experimentos com ratos que alterações nos níveis proteicos interferem na conjugação da glutationa que possui papel importante na rota de eliminação destas substâncias (Cheeke 2009). Esses fatos podem ter levado à ocorrência de lesões pouco freqüentes como lesões subagudas (Padrão 6) ou com menor quantidade de fibrose (Padrão 3).

O tempo de evolução dos sinais clínicos observados nos 35 surtos cujos fígados de animais necropsiados foram estudados não interferiu na apresentação dos diferentes padrões morfológicos observados. Cabe salientar que o tempo de evolução da enfermidade pode não ter sido informado exatamente. Muitas vezes as áreas de criação de bovinos não são vistoriadas diariamente e a doença só chama a atenção quando os bovinos apresentam sinais clínicos neu- rológicos, que frequentemente ocorrem já na fase terminal (Riet-Correa \& Méndez 2007). Como pode ser observado neste trabalho, quando o único sinal clínico relatado era relacionado ao sistema nervoso a evolução variava de 1-7 dias e animais com esse tempo de evolução apresentaram lesões com fibrose acentuada (Padrões 1, 2 e 4).

Com relação à idade dos animais, observou-se que dos 35 surtos estudados $34 \%$ ocorreram em animais abaixo de três anos e $60 \%$ em animais adultos. Não houve, também, uma relação direta da idade com os diferentes padrões de lesão observados. Embora a intoxicação por Senecio spp. seja considerada uma doença de animais adultos (Karam et al. 2004), este trabalho demonstra que apesar de ser mais frequente nesta categoria um número expressivo de animais menores de 3 anos pode ser afetado e sugere-se que isto esteja relacionado com o aumento da disponibilidade da planta e/ou aumento da concentração de APs em função da seca na região.

Degeneração de hepatócitos é observada com frequência em fígados de animais intoxicados por APs (Barros et al. 1987, 1992, Karam et al. 2004). Driemeier et al. (1991) mencionam esteatose hepatocelular em casos de intoxicação por APs. No presente trabalho, lesões degenerativas foram observadas no Padrão 5, que histologicamente se caracterizava por tumefação e vacuolização fina dos hepatócitos. No Padrão 2 vacúolos citoplasmáticos foram observados nos nódulos que macroscopicamente tinham aspecto claro, porém não foi determinada a natureza do material acumulado.

Neste trabalho, a grande maioria dos casos apresentou fibrose difusa, nódulos encarcerados por tecido fibroso ou fibrose em ponte e apenas em sete casos a fibrose era discreta. Isto concorda com a literatura a respeito, que tem demonstrado que a fibrose difusa é a lesão mais frequente em bovinos intoxicados Senecio spp. (Barros et al. 1987, 1992, Driemeier et al. 1991, Karam et al. 2004).

A regeneração de tecido hepático entre os feixes de tecido conjuntivo leva a formação de nódulos regenerativos de tamanhos variáveis (Cullen 2007). O termo nódulo regenerativo costuma ser empregado com frequência em medicina veterinária para designar nódulos macro e microscópicos que ocorrem na intoxicação por APs e por definição são constituídos de hepatócitos aparentemente normais (Méndez 1993). Nos fígados que foram classificados nos Padrões 2 e 3 neste estudo, os hepatócitos nos nódulos não eram normais uma vez que exibiam vacuolização do citoplasma ou megalocitose. Nódulos regenerativos são resultantes da proliferação de hepatócitos remanescentes em tentativas de restabelecer as funções hepáticas normais (Kellermann et al. 2005). Os APs são inibidores da mitose o que resulta em megalocitose, portanto é muito provável que os nódulos observados não sejam decorrentes de mitoses e sim de encarceramento em consequência da fibrose coalescente ao redor destes hepatócitos.

De acordo com os resultados obtidos no presente trabalho, a variação nos padrões macroscópicos e histológicos 
hepáticos observados em bovinos intoxicados por Senecio spp. parece não estar relacionada às variações epidemiológicas como idade dos animais afetados, tempo de evolução da enfermidade e época do ano. As variações climáticas, como a seca, provavelmente influíram no aumento da ocorrência da intoxicação pela maior disponibilidade da planta durante todo o ano o que poderia ter levado, também, à ocorrência de lesões com menor quantidade de fibrose em alguns casos observados nos anos que se seguiram a severa estiagem na região.

Agradecimentos.- Ao CNPq (Proc.573534/2008-0), pelo auxílio à pesquisa.

\section{REFERÊNCIAS}

Barros C.L.S., Metzdorf L.L. \& Peixoto P.V. 1987. Ocorrência de surtos de intoxicação por Senecio spp. (Compositae) em bovinos no Rio Grande do Sul. Pesq. Vet. Bras. 7(1):101-107.

Barros C.L.S., Driemeier D., Pilati C. \& Barros S.S. 1992. Senecio spp. poisoning in cattle in southern Brazil. Vet. Human Toxicol. 34(3):241246.

Berry D.M. \& Bras G. 1957. Venous occlusion of the liver in Crotalaria and Senecio poisoning. North. Am. Vet. 38:323-326.

Cheeke P.R. 2009. Nutritional implications of pyrrolizidine alkaloid toxicosis. Proc. $8^{\text {th }}$ International Symposium of Poisonous Plants, João Pessoa, Paraíba, Brasil, p.18.

Cullen J.M. 2007. Liver, biliary system and exocrine pancreas, p.426446. In: McGavin M.D. \& Zachary J.F. (Eds), Pathologic Basis of Veterinary Disease. $4^{\text {th }}$ ed. Mosby Elsevier, St Louis, Missouri.

Driemeier D., Barros C.S.L. \& Pilati C. 1991. Seneciose em bovinos. Hora Vet. 10(59):23-30.

Jago M.V. 1969. The development of the hepatic megalocytosis of chronic pyrrolizidine alkaloid poisoning. Am. J. Pathol. 56(3):405-420.

Karam F.S.C., Soares M.P., Haraguchi M., Riet-Correa F., Méndez M.C. \& Jarenkow J.A. 2004. Aspectos epidemiológicos da seneciose na região sul do Rio Grande do Sul. Pesq. Vet. Bras. 24:191-198.

Kellerman T.S., Coetzer J.A.W. \& Naudé T.W. 2005. Plant Poisonings and Mycotoxicoses of Livestock in Southern Africa. $2^{\text {nd }}$ ed. Oxford University Press, Cape Town, p.6-13.

Kelly W.R. 1993. The liver and biliary system, p.326-401. In: Jubb
K.V.F., Kennedy P.C. \& Palmer N. (Eds), Pathology of Domestic Animals. Vol.2. $4^{\text {th }}$ ed. Academic Press, San Diego, California.

Lindamood C. 1991. Xenobiotic Biotransformation, p.139-180. In: Meeks R.G., Harrison S.D. \& Bull R.J. (Eds), Hepatotoxicology. CRC Press, Boca Raton, Florida.

Marques J.R.Q. 2009. Comunicação pessoal (Faculdade de Meteorologia, Universidade Federal de Pelotas, Pelotas, RS).

Méndez M.C. \& Riet-Correa F. 1993. Intoxication by Senecio tweediei in cattle in southern Brazil. Vet. Hum. Toxicol. 35(1):55.

Méndez M.C. 1993. Intoxicações por plantas e micotoxinas hepatotóxicas, p.43-112. In: Riet-Correa F., Méndez M.C. \& Schild A.L. (Eds), Intoxicações por Plantas e Micotoxicoses em Animais Domésticos. Vol.1. Editorial Hemisfério Sul do Brasil, Pelotas.

Méndez M.C., Riet-Correa F. \& Schild A.L. 1987. Intoxicação por Senecio spp. (Compositae) em bovinos no Rio Grande do Sul. Pesq.Vet. Bras. 7(2):51-56.

Méndez M.C., Riet-Correa F., Schild A.L. \& Martz W. 1990. Intoxicação experimental por cinco espécies de Senecio em bovinos e aves. Pesq. Vet. Bras. 10(3/4):63-69.

Pedroso P.M.O., Raymundo D.L., Guagnini F.S., Oliveira E.C., Corrêa A.M.R., Colodel E.M. \& Driemeier D. 2005. Intoxicações por plantas e substâncias químicas em ruminantes diagnosticadas no Setor de Patologia Veterinária da UFRGS no período de 1997-2004. Arq. Bras. Med. Vet. Zootec. 57:74-75.

Riet-Correa F. \& Mendez M.C. 2007. Intoxicações por plantas e micotoxinas, p.99-221. In: Riet-Correa F., Schild A.L., Lemos R.A.A. \& Borges J.R. (Eds), Doenças de Ruminantes e Eqüídeos. Vol.2. $3^{a}$ ed. Gráfica e Editora Palotti, Santa Maria.

Rissi D.R., Rech R.R., Pierezan F., Gabriel A.L., Trost M.E., Brum J.S., Kommers G.D. \& Barros C.S.L. 2007. Intoxicações por plantas e micotoxinas associadas a plantas em bovinos no Rio Grande do Sul: 461 casos. Pesq. Vet. Bras. 27(7):261-268.

Schild A.L., Ferreira J.L.M., Ladeira S.R.L., Soares M.P., Grecco F.B., Marcolongo-Pereira C. \& Fiss L. 2008. Doenças diagnosticadas pelo Laboratório regional de Diagnóstico no ano 2007. Boletim do Laboratório Regional de Diagnóstico. Editora Universitária, UFPel, Pelotas, p.60-63.

Tokarnia C.H., Döbereiner J. \& Peixoto P.V. 2000. Plantas Tóxicas do Brasil. Editora Helianthus, Rio de Janeiro, p.98-109.

Torres M.B.A. \& Coelho K.I.R. 2008. Experimental poisoning by Senecio brasiliensis in calves: Quantitative and semi-quantitative study on changes in the hepatic extracellular matrix and sinusoidal cells. Pesq. Vet. Bras. 28(1):43-50. 